\title{
Studi Struktur Komunitas Padang Lamun Di Pulau Parang, Kepulauan Karimunjawa
}

\author{
Amin Nur Kolis Rela Hidayah*, Raden Ario, Ita Riniatsih \\ Departemen IImu Kelautan, Fakultas Perikanan dan IImu Kelautan, Universitas Diponegoro \\ JI. Prof.H.Soedarto S.H, Tembalang,Semarang, Jawa Tengah 50275 Indonesia \\ *Corresponding author, e-mail : aminnurkolis@student.undip.ac.id
}

\begin{abstract}
ABSTRAK : Struktur komunitas lamun merupakan suatu konsep yang harus diketahui untuk mengetahui kondisi ekosistem perairan tersebut. Padang lamun memiliki peran penting dalam kehidupan yang ada dibawah laut dangkal, sehingga ekosistem padang lamun perlu untuk dijaga kelestariannya agar keberlangsungan produktivitas di ekosistem tersebut tetap seimbang. Tujuan penelitian ini adalah menghitung dan menganalisis komposisi jenis, kerapatan serta persen tutupan lamun, mengetahui indeks ekologi lamun seperti keanekaragaman, keseragaman, dominansi dan mengetahui indeks nilai penting lamun di Pulau Parang. Penelitian dilakukan pada bulan Agustus sampai September 2017. Metode penelitian menggunakan metode deskriptif, terdapat 2 lokasi (A dan B) dengan 3 stasiun disetiap lokasinya. Penentuan lokasi dengan metode purposive random sampling. Pada saat penelitian, setiap stasiun menggunakan transek kuadran ukuran $1 \times 1 \mathrm{~m}$ pada hamparan lamun. Transek ini dibagi menjadi 16 buah kisi ukuran $25 \mathrm{~cm}^{2}$. Jumlah tegakan diamati langsung secara visual. Hasil penelitian menunjukkan 4 jenis lamun, yaitu Enhalus acoroides, Halophila ovalis, Cymodocea rotundata dan Thalassia hemprichii. Kisaran kerapatan lamun yang ditemukan 5-219 tegakan $/ \mathrm{m}^{2}$. Rata-rata persen tutupan lamun menunjukkan nilai 17,61\% (Lokasi A) dan 19,24\% (Lokasi B). Indeks Nilai Penting menunjukkan Cymodocea rotundata berperan penting dalam kondisi ekosistem perairan di lokasi A dan B . Indeks ekologi lamun menunjukkan bahwa nilai keanekaragaman tergolong sedang di Lokasi $A$ dan rendah di Lokasi $B$, sedangkan nilai keseragaman tergolong tinggi di Lokasi $A$ dan sedang di Lokasi $\mathrm{B}$ dan nilai dominansi tergolong sedang di Lokasi A dan tinggi di Lokasi B.
\end{abstract}

Kata kunci: Komunitas; Lamun; Pulau Parang

\section{Study of Padang Seagrass Community Structure on Parang Island, Karimunjawa Archipelago}

\begin{abstract}
The seagrass community structure is the concept that must be known to determine the condition of the aquatic ecosystem. Due to the fact thar seagrass beds have an important role in life under the shallow sea, the seagrass ecosystem needs to be preserved so that the sustainability of productivity in the ecosystem remains balanced. The purpose of this study was to calculate and analyze the species composition, density and the precentage of seagrass cover, to know the index of seagrass ecology such as diversity, uniformity, dominance and to know the important value index of seagrass in Parang Island. The study was conducted from August to September 2017. The research method used a descriptive method, there were 2 locations ( $A$ and $B$ ) with 3 stations in each location. The determination of location was done by doing a purposive random sampling method. During the research, each station used a $1 \times 1 \mathrm{~m}$ quadrant transect on a seagrass bed. This transect was divided into 16 lattice sizes of $25 \mathrm{~cm}^{2}$. The number of stands was observed visually. The results of this research showed that there were 4 types of seagrass, such as Enhalus acoroides, Halophila ovalis, Cymodocea rotundata and Thalassia hemprichii. The seagrass density that found was 5-219 stands $/ \mathrm{m}^{2}$. The percentage of seagrass cover showed a value of $17.61 \%$ (Location A) and $19.24 \%$ (Location B). Important Value Index showed that Cymodocea rotundata plays an important role in the condition of aquatic ecosystems in locations $A$ and $B$. The seagrass ecology index showed that the diversity value is classified as medium in
\end{abstract}


Location $A$ and low in Location B. Uniformity values are high in Location $A$ and medium in Location $B$ and dominance values are medium in Location $A$ and high in Location $B$.

Keywords: Community; Seagrass; Parang Island

\section{PENDAHULUAN}

Lamun merupakan tumbuhan berbiji satu (monokoti) yang mempunyai akar rimpang (rhizoma), daun, bunga, dan buah. Hamparan lamun di perairan pesisir yang tersusun atas satu atau lebih jenis dikenal sebagai padang lamun. Lamun dapat ditemukan di seluruh dunia kecuali di daerah kutub. Lebih dari 52 jenis lamun yang telah ditemukan. Lamun di Indonesia terdapat 2 suku yaitu Hydrocaritaceae dan Potamogetonaceae, yang terdiri dari 7 marga dan 13 jenis (Hardiyanti et al, 2009).

Indonesia sebagai negara kepulauan yang memiliki luas laut lebih besar dari pada luas daratan. Wilayah laut Indonesia yang terletak pada garis khatulistiwa terkenal memiliki kekayaan dan keanekaragaman sumberdaya hayati dan non hayati laut. Wilayah pesisir yang merupakan wilayah peralihan antara ekosistem darat dan laut, memiliki potensi sumberdaya alam yang sangat besar terutama pada tiga ekosistem utama yaitu ekosistem mangrove, padang lamun, dan terumbu karang. Lamun merupakan tumbuhan berbunga (Angiospermae) yang hidup dan berkembang biak pada lingkungan perairan laut dangkal.

Kepulauan Karimunjawa memiliki beberapa pulau kecil dengan ekosistem pesisir yang sangat penting yaitu terumbu karang, padang lamun, dan hutan mangrove. Selain itu banyak jenis yang dilindungi berada di Kepulauan Karimunjawa seperti penyu hijau, penyu sisik, paus, kima dan lain - lain (Hartati et al., 2012).

Pulau Parang terletak di gugusan Kepulaun Karimunjawa, Kabupaten Jepara, Jawa Tengah. Pulau Parang dijadikan sebagai lokasi penelitian karena kawasan ini merupakan perairan dengan hamparan lamun yang cukup luas. Selain itu, Pulau Parang memiliki beragam spesies lamun, diantaranya Thallassia hemprichii, Enhalus acoroides, Cymodocea rotundata, Cymodocea serrulata, Halodule pinifolia, Halodule uninervis, dan Halophila ovalis. Serta sekeliling Pulau Parang memiliki substrat yang bermacam - macam yang memungkinkan disekitar Pulau Parang memiliki beragam spesies lamun (Hardiyanti et al., 2009).

\section{METODE PENELITIAN}

Materi yang digunakan dalam penelitian ini tumbuhan lamun yang tumbuh dari daerah padang lamun di perairan Pulau Parang, Karimunjawa. Parameter kualitas air di ukur secara "in situ" bersama dengan pengambilan sampel lamun. Parameter tersebut meliputi kedalaman (m), $\mathrm{pH}$, suhu $\left({ }^{\circ} \mathrm{C}\right)$ dan salinitas (ppt). Metode yang digunakan dalam penelitian ini adalah dengan menggunakan metode deskriptif. Metode deskriptif adalah metode penelitian yang dimaksudkan untuk mengumpulkan informasi mengenai status suatu gejala yang ada, yaitu keadaan gejala menurut apa adanya pada saat penelitian dilakukan (Arikunto, 2006). Lokasi penelitian dibagi menjadi 2 lokasi yaitu lokasi A dan B dengan setiap lokasinya dibagi lagi menjadi 3 line transect sedangkan jarak antara line transect adalah $50 \mathrm{~m}$ (Gambar 1). Penentuan lokasi penelitian tersebut berdasarkan persentase kerapatan padang lamun dimana setiap stasiunnya dapat mewakili karakteristik lokasi penelitian tersebut. Penentuan lokasi penelitian ini dengan mempertimbangkan perbedaan jenis lamun dan kerapatan lamun yang berada di masing - masing lokasi penelitian.

Pengamatan lamun di lapangan meliputi identifikasi jenis-jenis lamun, menghitung jumlah individu/tegakan berdasarkan metode English et al. (1994) dengan jarak antar titik sampling yaitu $10 \mathrm{~m}$ tegak lurus garis pantai dan jarak antar line transect $50 \mathrm{~m}$ sejajar garis pantai, serta indeks dari masing - masing jenis/spesies pada setiap transek. Persen penutupan lamun diamati dengan menggunakan transek kuadrat ukuran $1 \times 1 \mathrm{~m}$ pada hamparan lamun. Transek ini dibagi menjadi 16 buah kisi ukuran $25 \mathrm{~cm}^{2}$. Satu tegakan lamun merupakan suatu kumpulan dari beberapa daun yang pangkalnya menyatu. Jumlah tegakan diamati langsung secara visual. 
Untuk mengetahui kondisi ekosistem lamun dilakukan dengan menghitung komposisi jenis lamun, kerapatan jenis lamun dan persen tutupan lamun. Indeks ekologi seperti indeks keanekaragaman, keseragaman dan dominansi dihitung untuk mendukung data mengenai kondisi lamun di perairan Pulau Parang. Untuk menduga keseluruhan dari peranan dari suatu jenis lamun dilakukan perhitungan indeks nilai penting lamun.

Kerapatan jenis lamun adalah jumlah individu/tegakan per satuan luas. Kepadatan masing masing jenis lamun pada setiap stasiun dihitung dengan menggunakan rumus (Fachrul, 2007):

$$
D_{i}=\frac{N_{i}}{A}
$$

Keterangan: $\mathrm{Di}=$ Kerapatan jenis $\mathrm{ke}-\mathrm{i}\left(\right.$ tegakan $\left./ \mathrm{m}^{2}\right) ; \mathrm{Ni}=$ Jumlah individu ke $-\mathrm{i}$ dalam kuadrat (tegakan); $\mathrm{A}=$ Luas transek kuadran $\left(\mathrm{m}^{2}\right)$

Penutupan lamun menyatakan luasan area yang tertutupi oleh lamun. Persen penutupan lamun dihitung dengan metode Saito and Atobe. Dengan menggunakan rumus (Fachrul, 2007):

$$
C i=\frac{\sum(M i \times f i)}{\sum f}
$$

Keterangan: $\mathrm{Ci}=$ Penutupan (\%); $\mathrm{Mi}=$ Nilai tengah kelas $\mathrm{I} ; \mathrm{F}=$ Frekuensi (jumlah kisi yang memiliki nilai kelas yang sama)

Keanekaragaman, keseragaman dan dominansi lamun ditentukan dari besar nilai indeks yang ada. Indeks keanekaragaman, keseragaman dan dominansi dihitung dengan menggunakan rumus Shamon - Weanner (Fachrul, 2007):

$$
\begin{gathered}
\mathrm{H}^{\prime}=-\sum_{i=1}^{n}\left(p i \log _{2} p i\right. \\
\mathrm{Pi}=\frac{n i}{N}
\end{gathered}
$$

Keterangan: $\mathrm{H}^{\prime}=$ Indeks keseragaman; $\mathrm{Ni}=$ Jumlah individu jenis ke-I; $\mathrm{n}=$ Jumlah spesies; $\mathrm{N}=$ Jumlah individu total; $\mathrm{Pi}=$ Proporsi frekuensi jenis $\mathrm{ke}-\mathrm{i}$ terhadap jumlah total
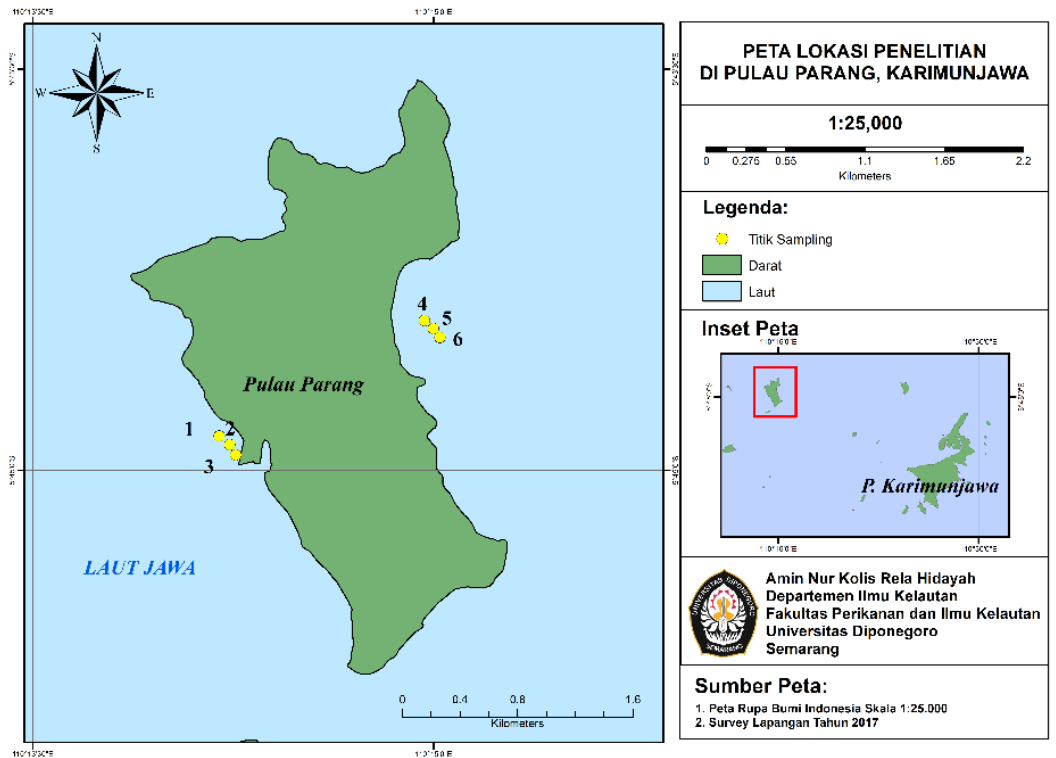

Gambar 1. Lokasi Penelitian Studi Struktur Komunitas Lamun di Pulau Parang, Kepulauan Karimunjawa

Kriteria dari indeks keanekaragaman ditentukan berdasarkan nilai yang didapat (Fachrul, 2007): $H^{\prime}<1=$ keanekaragaman rendah; $1 \leq H^{\prime} \leq 3=$ keanekaragaman sedang $H^{\prime}>3=$ keanekaragaman tinggi

Indeks keseragaman dihitung dengan menggunakan rumus (Fachrul, 2007): 


$$
\begin{gathered}
E=\frac{H^{\prime}}{H_{\text {maks }}} \\
H_{\text {maks }}=\log _{2} S=3.3219 \log S
\end{gathered}
$$

Keterangan: $\mathrm{E}=$ indeks keseragaman; $\mathrm{S}=$ jumlah spesies; Nilai indeks keseragaman berkisar antara 0 - 1, dengan kategori: $\mathrm{E}<0.4=$ keseragaman rendah; $0,4 \leq \mathrm{E} \leq 0,6=$ keseragaman sedang; E>0.6 = keseragaman tinggi

Indeks Dominansi dihitung dengan menggunakan rumus (Fachrul, 2007):

$$
\mathrm{D}=\sum_{i=I}^{n}(p i)^{2}
$$

Keterangan: $\mathrm{D}=$ Indeks dominansi; $\mathrm{Pi}=$ Proporsi jumlah ke $-\mathrm{i}$ terhadap jumlah total; $\mathrm{N}=$ Jumlah spesies. Kategori indeks dominansi dapat dikelompokkan menjadi: $\mathrm{D}<0,4=$ Dominansi rendah; $0,4 \leq \mathrm{D} \leq 0,6=$ Dominansi sedang; $\mathrm{D}>0.6=$ Dominansi tinggi

Indeks nilai penting lamun (INP) digunakan untuk menghitung dan menduga secara keseluruhan dari peranan satu spesies di dalam suatu komunitas. Rumus yang digunakan adalah (Brower et al, 1990):

$$
I N P=R F i+R D i+R C i
$$

Keterangan: INP = Indeks Nilai Penting; RFi = Frekuensi Relatif (\%); RDi = Kerapatan Relatif $(\%)$; $\mathrm{RCi}=$ Penutupan Relatif (\%)

\section{HASIL DAN PEMBAHASAN}

Pulau Parang terletak pada koordinat $110^{\circ} 13^{\prime} 7,6^{\prime \prime}$ - $110^{\circ} 15^{\prime} 59,94^{\prime \prime}$ BT dan $05^{\circ} 46^{\prime} 18,70^{\prime \prime}-$ $05^{\circ} 43^{\prime} 27,78^{\prime \prime}$ LS. Pulau ini merupakan salah satu pulau yang berada di wilayah konservasi Balai Taman Nasional Karimunjawa, pulau yang berpenghuni ini termasuk dalam zona pemukiman dan untuk pemanfaatan sumber daya pulai ini termasuk dalam zona budidaya bahari. Pulau ini disekelilingnya banyak ditumbuhi karang sehingga kapal cukup susah untuk merapat ke tepi pantai.

Hasil dari penelitian menunjukkan terdapat 4 spesies lamun yang ditemukan di Pulau Parang yaitu Enhalus acoroides, Cymodocea rotundata, Halophila ovalis dan Thalassia hemprichii. Jenis lamun yang ditemukan pada lokasi penelitian tersaji dalam Tabel 1. Kedua lokasi yang diambil data sampel berdekatan dengan ekosistem mangrove dan memiliki karakteristik yang berbeda.

Keadaan lokasi A berada didekat pelabuhan dimana banyak lalu lalang kapal keluar masuk serta aktivitas penduduk yang ada disekitar lokasi tersebut. Selain itu lokasi tersebut lebih banyak ditumbuhi oleh spesies Enhalus acoroides. Lokasi ini sering sekali terkena ombak yang cukup besar dikarenakan berhadapan langsung dengan perairan terbuka. Pada lokasi tersebut memiliki substrat dengan pasir berlumpur dengan kedalaman antara 0,4 m sampai $1 \mathrm{~m}$.

Lokasi B berada cukup jauh dari pemukiman penduduk sehingga sedikit sekali masyarakat penduduk yang beraktivitas di lokasi tersebut. Lokasi B ini terdapat banyak tumbuhan mangrove dan berhadapan langsung dengan terumbu karang. Di dalamnya terdapat beberapa biota laut seperti kima, ikan, teripang dan bulu babi. Dan di lokasi tersebut memiliki spesies Cymodocea rotundata dan Halophila ovalis yang cukup melimpah. Kondisi cuaca ketika pengambilan data cukup cerah dan tidak berawan. Serta lokasi ini berada di cekungan pulau sehingga ombak di lokasi tersebut cukup tenang. Pada lokasi tersebut memiliki substrat dengan pasir dan pecahan karang dengan kedalaman antara $0,5 \mathrm{~m}$ sampai $1 \mathrm{~m}$.

Lamun dari kedua lokasi dan keenam stasiun yang telah diambil sampelnya, diketahui bahwa komposisi dari kedua lokasi tersebut ada perbedaannya. Diantaranya adalah pada lokasi $\mathrm{A}$ ditemukan spesies lamun Enhalus acoroides, sedangkan pada lokasi B tidak ditemukan sama sekali. Hal ini bisa saja terjadi karena ada beberapa faktor seperti substrat yang ada di lokasi tersebut. Lokasi A memiliki substrat dasar berpasir dan sedikit berlumpur, hal ini sesuai dengan yang dikatakan oleh Philips dan Menez (1998), bahwa Enhalus acoroides hidup pada perairan dengan substrat pasir atau lumpur. Selain itu lokasi A berada di titik yang berhadapan langsung dengan perairan terbuka, sehingga sering diterjang oleh ombak yang cukup besar. Hal ini sesuai dengan morfologi yang dimiliki oleh Enhalus acoroides yaitu memiliki rambut - rambut kaku dengan lebar lebih dari 1,5 cm serta akar yang banyak dan bercabang (Irawan dan Matuankotta, 
2015). Thomascik et al. (1997) menyampaikan bahwa akar Enhalus acoroides dapat mencapai panjang lebih dari $50 \mathrm{~cm}$ sehingga dapat menancap secara kuat pada substrat.

Sedangkan pada lokasi B komposisi jenis lamun Cymodocea rotundata dan Halophila ovalis cukup melimpah serta tidak terdapat Enhalus acoroides. Hal ini diduga karena substrat yang ada pada lokasi B memiliki tipe substrat pasir dan pecahan karang, dimana substrat tersebut mendukung untuk pertumbuhan spesies lamun Cymodocea rotundata. Sesuai dengan apa yang dikatakan oleh Kuo dan Den Hartog (2006), bahwa Cymodocea rotundata tumbuh pada substrat pasir berlumpur atau pasir dengan pecahan karang. Berbeda dengan Halophila ovalis, spesies lamun tersebut tumbuh pada substrat pasir berlumpur, dimana substrat tersebut terdapat pada stasiun B2 tumbuhan tersebut melimpah di stasiun tersebut. Pernyataan tersebut didukung Purnama et al. (2013), bahwa Halophila ovalis tumbuh di substrat pasir berlumpur. Selain itu lokasi $\mathrm{B}$ berada di balik pulau sehingga terlindung dari terjangan ombak secara langsung, dimana Cymodocea rotundata ataupun Halophila ovalis tidak memiliki akar yang sekuat Enhalus acoroides untuk meredam gelombang datang, sehingga keduanya mampu tumbuh subur dan melimpah di lokasi tersebut karena memiliki gelombang laut yang tidak terlalu besar.

Terdapat perbedaan nilai kerapatan lamun antar stasiun pengamatan dapat di lihat pada Gambar 2. Perhitungan tingkat kerapatan berdasarkan pada jumlah setiap stasiun pada masing masing plot. Kerapatan lamun tertinggi ditemukan pada stasiun B2 dengan spesies Cymodocea rotundata sebanyak 219 tegakan $/ \mathrm{m}^{2}$. Sedangkan kerapatan lamun terendah ditemukan pada stasiun A2 dengan spesies Thalassia hemprichii sebanyak 5 tegakan $/ \mathrm{m}^{2}$. Kerapatan tertinggi ditemukan pada stasiun B2 dengan tingkat kerapatan 219 tegakan $/ \mathrm{m}^{2}$ dari spesies Cymodocea rotundata. Stasiun ini memiliki tipe substrat pasir dengan pecahan - pecahan karang. Menurut Hemminga dan Duarte (2000), jenis lamun Cymodocea rotundata banyak dijumpai di perairan yang dangkal namun tetap terendam air sehingga tidak langsung terpapar oleh sinar matahari maupun udara. Hal ini sesuai dengan stasiun tersebut yang memiliki kedalaman sekitar 0,7 m.

Tabel 1. Komposisi Jenis Lamun yang di Setiap Lokasi di Perairan Pulau Parang.

\begin{tabular}{cccccc}
\hline & & \multicolumn{5}{c}{ Spesies } \\
\cline { 3 - 7 } Lokasi & Stasiun & Cymodocea rotundata & $\begin{array}{c}\text { Enhalus } \\
\text { acoroides }\end{array}$ & Halophila ovalis & Thalassia hemprichii \\
\hline \multirow{2}{*}{$\mathrm{A}$} & 1 & + & + & + & - \\
& 2 & + & + & - & + \\
& 3 & + & + & - & - \\
$\mathrm{B}$ & 1 & + & - & + & - \\
& 2 & + & - & + & - \\
\hline
\end{tabular}

Keterangan : + : ditemukan; - : tidak ditemukan

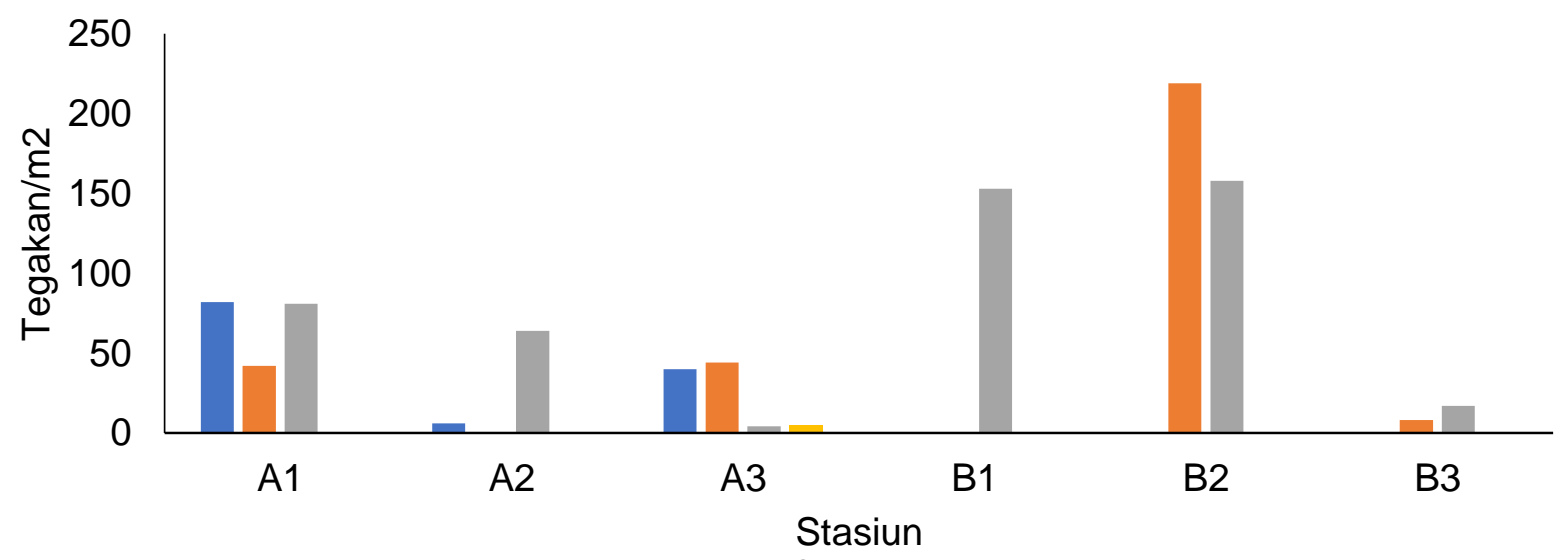

Enhalus acoroides $\square$ Halophila ovalis $\square$ Cymodocea rotundata $\square$ Thallasia hemprichii

Gambar 2. Tingkat Kerapatan Lamun di Perairan Pulau Parang (Tegakan $/ \mathrm{m}^{2}$ ) 
Suhu berpengaruh terhadap sifat fisiologi organisme perairan merupakan salah satu faktor yang mempengaruhi fotosintesis. Suhu rata - rata untuk pertumbuhahn lamun berkisar antara 24$27^{\circ} \mathrm{C}$. Suhu air dibagian pantai biasanya sedikit lebih tinggi daripada yang di lepas pantai, suhu permukaan di perairan nusantara umumnya berada dalam kisaran $28-30^{\circ} \mathrm{C}$. Sedangkan pada lokasi yang sering terjadi kenaikan massa air (upwelling), suhu permukaan bisa menurun sekitar $25{ }^{\circ} \mathrm{C}$ (Nontji, 1993). Lamun memiliki kemampuan toleransi yang berbeda terhadap salinitas, toleransi lamun terhadap salinitas bervariasi antar jenis dan umur lamun (Supriyadi dan Kuriandewa, 2008). Berdasarkan hasil perhitungan menunjukkan perbedaan nilai persentase tutupan setiap stasiun pada Gambar 3. Hasil menunjukkan bahwa terdapat perbedaan nilai persentase penutupan lamun pada setiap stasiun. Persentase penutupan lamun rata - rata terluas terdapat pada stasiun B2 (32,28\%) dan persentase penutupan terendah pada stasiun B3 $(8,75 \%)$.

Persentase penutupan lamun yang berbeda di setiap stasiun diduga dipengaruhi oleh morfologi lamun. Penutupan total lamun tertinggi tercatat pada stasiun B2 sebesar $32,38 \%$ dengan ditemukan dua jenis lamun. Dengan spesies tertinggi Cymodocea rotundata sebesar $46,15 \%$ dan Halophila ovalis sebesar $18.41 \%$. Penutupan lamun terendah berada pada stasiun B3 dengan ditemukan 2 jenis lamun, diantaranya Cymodocea rotundata dan Halophila ovalis. Jenis lamun Cymodocea rotundata mempunyai tutupan paling tinggi sebesar $46,15 \%$. Hal ini disebabkan oleh karakter jenis lamun itu sendiri yang hidup secara mengelompok dengan lamun lain yang sejenis dan substrat yang mendukung jenis lamun tersebut untuk hidup dan tumbuh.

Secara keseluruhan kedua lokasi tersebut jika dilihat dari persentase tutupan lamun tergolong rendah dengan nilai rata - rata lokasi A 17,61\% dan lokasi B 29,24\%. Hal ini dapat terjadi karena diduga adanya beberapa faktor seperti tingginya kadar salinitas pada lokasi penelitian diduga juga menjadi salah satu faktor rendahnya tutupan lamun. Tingginya salinitas dikarenakan ekosistem lamun yang cukup jauh dari daratan sehingga tidak mendapatkan pasokan air tawar dari darat untuk pertumbuhan lamun yang baik dan persen tutupan yang cukup merata. Menurut Feryatun et al. (2012), bahwa salah satu faktor yang menyebabkan kerusakan lamun adalah meningkatnya salinitas yang diakibatkan oleh kurangnya suplai air tawar. Hal ini terkait kemampuan toleransi lamun terhadap fluktuasi perubahan salinitas dengan kisaran 24 hingga 35 ppt. Selain itu banyaknya aktivitas masyarakat sekitar yang terjadi di lokasi A berdekatan dengan pelabuhan sehingga banyak kapal yang lalu lalang di lokasi tersebut. Hal ini diduga dapat merusak ekosistem lamun ketika sedang melintas.

Berdasarkan hasil yang didapat untuk mencari nilai indeks keanekaragaman, indeks keseragaman dan indeks dominansi, setiap stasiun didapatkan kategori untuk indeks keanekaragaman yaitu rendah dan sedang. Untuk indeks keseragaman didapatkan semua kategori yaitu rendah, sedang dan tinggi. Untuk indeks dominansi didapatkan semua kategori yaitu, rendah, sedang dan tinggi. Untuk nilai keanekaragaman, keseragaman dan dominansi bisa dilihat pada Tabel 2.

Nilai keanekaragaman tertinggi terdapat pada $A 1$ dengan nilai 1,526 dan nilai terendah terdapat pada B1 dengan nilai 0 . Nilai keseragaman tertinggi terdapat pada B2 dengan nilai 0,981 dan terendah terdapat pada B1 dengan nilai 0 . Nilai dominansi tertinggi terdapat pada B1 dengan nilai 1 dan terendah terdapat pada A1 dengan nilai 0,36. Grafik Indeks ekologi dapat dilihat pada Gambar 4.

Tabel 2. Keanekaragaman, Keseragaman dan Dominansi di Perairan Pulau Parang, Karimunjawa

\begin{tabular}{cccccccc}
\hline \multirow{2}{*}{ Lokasi } & \multirow{2}{*}{ Stasiun } & \multicolumn{7}{c}{ Indeks Ekologi } \\
\cline { 3 - 8 } & & \multicolumn{2}{c}{ Keanekaragaman $\left(\mathrm{H}^{\prime}\right)$} & \multicolumn{2}{c}{ Keseragaman $(\mathrm{E})$} & \multicolumn{2}{c}{ Dominasi $(\mathrm{D})$} \\
\hline \multirow{2}{*}{$\mathrm{A}$} & 1 & 1,53 & Sedang & 0,96 & tinggi & 0,36 & rendah \\
& 2 & 0,75 & Rendah & 0,47 & sedang & 0,74 & tinggi \\
& 3 & 1,22 & Sedang & 0,77 & tinggi & 0,46 & sedang \\
\hline \multirow{2}{*}{ B } & 1 & 0 & Rendah & 0 & rendah & 1 & tinggi \\
& 2 & 0,98 & Rendah & 0,98 & tinggi & 0,51 & sedang \\
& 3 & 0,90 & Rendah & 0,57 & sedang & 0,56 & sedang \\
\hline
\end{tabular}




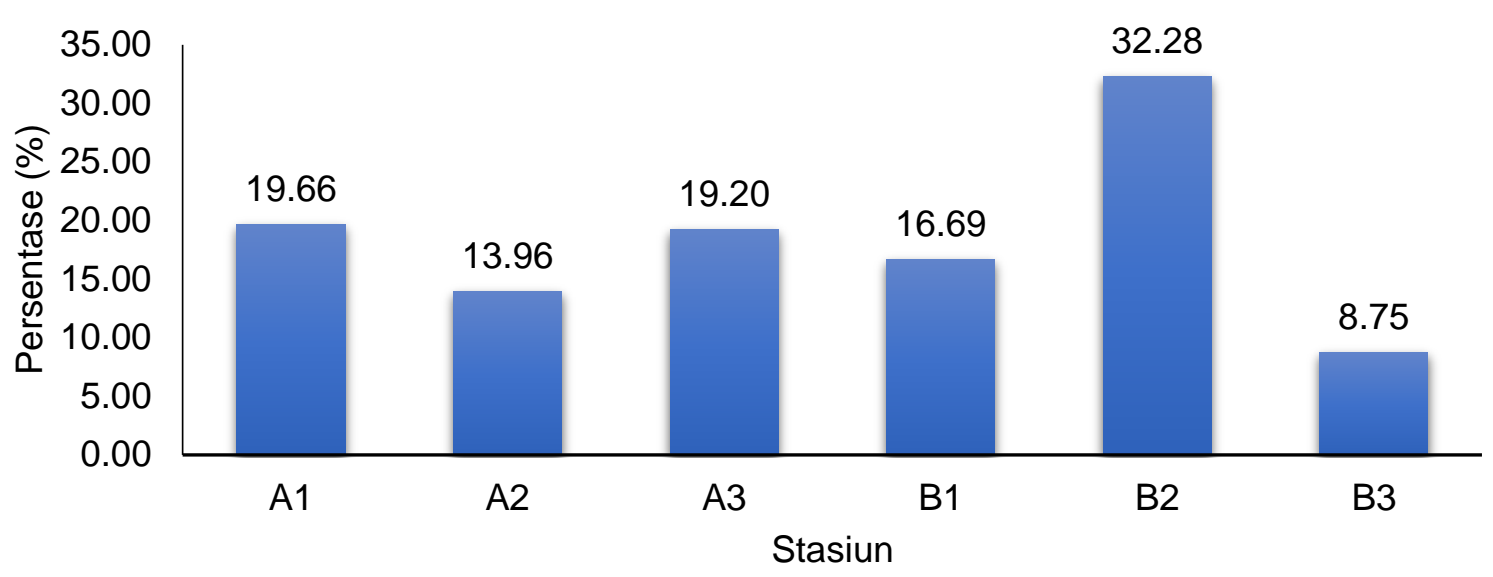

Gambar 3. Persentase Tutupan Lamun (\%) di Perairan Pulau Parang, Karimunjawa

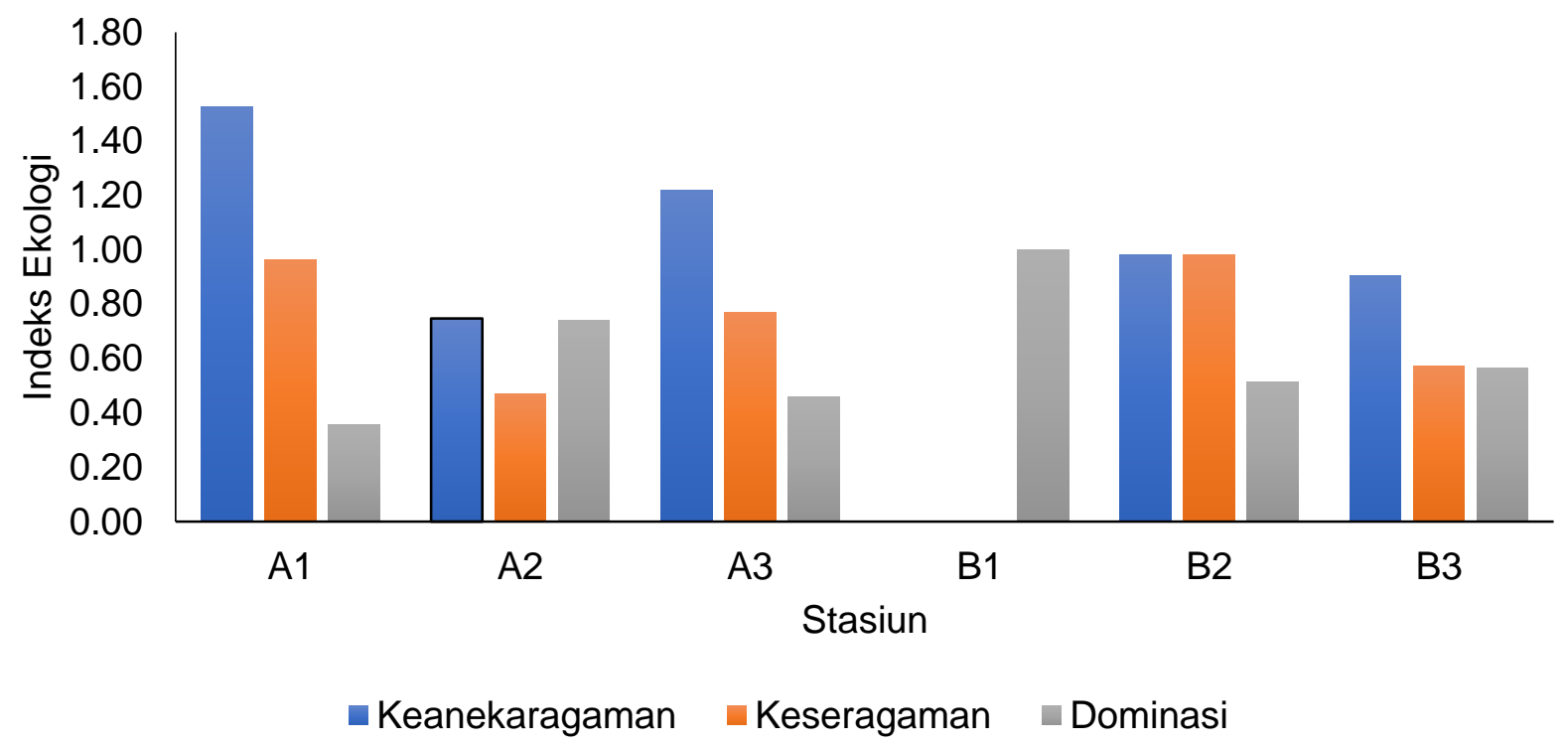

Gambar 4. Indeks Ekologi Lamun di Perairan Pulau Parang, Karimunjawa

Hasil penelitian menjelaskan bahwa indeks keanekaragaman di perairan Pulau Parang, Karimunjawa adalah berkategori rendah. Stasiun A1 memiliki nilai keanekaragaman tertinggi bila dibandingkan dengan stasiun yang lain yang masuk dalam kategori sedang. Untuk stasiun B1 memiliki nilai keanekaragaman terendah dengan kategori rendah. Menurut Nybakken (1992) keanekaragaman suatu komunitas yang bernilai tinggi menunjukkan bahwa pada daerah tersebut memiliki ekosistem yang nyaman, seimbang atau stabil dan memberikan peranan yang besar untuk menjaga keseimbangan terhadap gangguan yang merusak ekosistem. Menurut Odum (1996) keanekaragaman mempunyai nilai tertinggi jika semua individu berasal dari spesies yang berbeda - beda. Sebaliknya nilai terkecil diperoleh jika individu berasal dari spesies yang sama, yang mana itu terjadi seperti yang ada di stasiun B1 yang hanya terdapat Cymodocea rotundata. Hal ini dapat terjadi karena pada lokasi B, terutama di stasiun B1 memiliki karakteristik substrat yang didominasi oleh pasir dengan pecahan karang. Kondisi ini sesuai dengan karakteristik Cymodocea rotundata yang dapat tumbuh dengan baik pada substrat tersebut. Salinitas yang baik bagi kehidupan lamun berada pada kisaran 10 - 40 ppt. menurut Short dan Coles (2003), salinitas yang terlalu tinggi dapat menjadi faktor pembatas bagi penyebaran lamun, menimbulkan stress osmotis dan menurunkan daya tahan terhadap penyakit. Kondisi salinitas di seluruh stasiun menunjukkan suatu rentang salinitas yang berada di batas atas kisaran salinitas yang baik bagi tumbuhan lamun, dimana salinitas ini menjadi salah satu faktor sedikitnya hasil penelitian yang didapat. 
Nilai keseragaman di perairan Pulau Parang, Karimunjawa memiliki kategori yang cukup tinggi jika dilihat dari keseluruhan stasiun. Menurut Ruswahyuni (2008), semakin kecil indeks keseragaman maka semakin besar perbedaan jumlah antara spesies sedangkan semakin besar indeks keseragaman maka semakin kecil perbedaan jumlah antara spesies sehingga kecenderungan dominasi oleh jenis tertentu. Nilai indeks keseragaman stasiun B1 yang berkategori rendah, ini dapat terjadi karena dalam stasiun tersebut hanya terdapat satu spesies yaitu hanya ditemukan spesies Cymodocea rotundata yang tumbuh, sehingga nilai keseragamannya memiliki nilai 0 , diduga spesies yang mampu hidup di stasiun B1 dengan substrat pasir dan pecahan karang hanya Cymodocea rotundata, selain itu fluktuasi perubahan salinitas yang tinggi menjadi salah satu factor sebagai pembatas pertumbuhan lamun di stasiun tersebut.

Indeks dominansi lamun di perairan Pulau Parang, Karimunjawa berkisar 0,36 - 1. Nilai indeks dominansi lamun tertinggi di stasiun B1 dengan nilai 1 sedangkan nilai terendah pada stasiun A1 dengan nilai 0,36. Hal ini sesuai dengan pendapat Syamsurisal (2011), bahwa jika indeks dominansi 0 berarti hampir tidak ada jenis lamun yang mendominasi dan apabila nilai indeks dominasi mendekati 1 berarti ada salah satu jenis yang mendominasi. Seperti yang terjadi pada stasiun B1, hanya ada satu spesies yang terdapat pada stasiun tersebut, sehingga nilai dominansinya tinggi yaitu bernilai 1 . Hal ini disebabkan oleh substrat yang terdapat pada stasiun B1 yang sebagian besar adalah pasir bercampur dengan pecahan karang. Jenis substrat dasar juga merupakan faktor pembatas dalam kehidupan lamun (Tangke, 2010).

Indeks nilai penting merupakan suatu nilai dari penjumlahan nilai frekuensi relatif, kerapatan relatif dan penutupan relatif. Berdasarkan hasil perhitungan tersebut menunjukkan perbedaan nilai indeks nilai penting setiap stasiun pada Tabel 3 di bawah ini.

Indeks nilai penting pada suatu kondisi vegetasi ekosistem sangat memengaruhi lingkungan perairan tersebut. Seperti yang terjadi pada stasiun B2, indeks nilai penting tertinggi dimiliki oleh Cymodocea rotundata dengan nilai $300 \%$. Hal ini dapat terjadi karena pada stasiun tersebut hanya terdapat satu spesies saja yaitu Cymodocea rotundata itu sendiri, sehingga spesies tersebut yang hanya berpengaruh pada lingkungan tersebut. Mungkin akan berbeda halnya dengan yang ada di stasiun A3 atau stasiun yang lainnya. Pada stasiun tersebut terdapat dua atau lebih spesies lamun yang tumbuh. Sehingga spesies yang berpengaruh terhadap lingkungan di stasiun tersebut tidak hanya satu spesies tetapi banyak spesies. Pada stasiun A3 terdapat tiga spesies, yaitu Enhalus acoroides dengan nilai 147\%; Halophila ovalis dengan nilai 116\%; dan Cymodocea rotundata dengan nilai 36\%. Dari ketiga spesies tersebut, Enhalus acoroides memiliki nilai yang lebih tinggi dibandingkan yang lainnya, sehingga dapat dikatakan spesies tersebut memiliki peran yang paling penting pada stasiun tersebut. Tinggi rendahnya suatu indeks nilai penting dapat dipengaruhi oleh berbagai faktor, seperti jumlah spesies yang lebih banyak, kerapatan yang lebih tinggi serta persentase tutupan yang lebih besar. Namun jika ketiga faktor tersebut memiliki nilai yang rendah, maka indeks nilai penting suatu spesies juga rendah. Seperti spesies Cymodocea rotundata di stasiun A3 yang hanya memiliki nilai $36 \%$. Sehingga spesies tersebut tidak cukup berperan pada ekosistem di stasiun tersebut.

Tabel 3. Indeks Nilai Penting di Perairan Pulau Parang, Karimunjawa

\begin{tabular}{cccccc}
\hline \multirow{2}{*}{ Lokasi } & Stasiun & \multicolumn{4}{c}{ Indeks Nilai Penting (\%) } \\
\cline { 3 - 6 } & & Halophila ovalis & $\begin{array}{c}\text { Enhalus } \\
\text { acoroides }\end{array}$ & $\begin{array}{c}\text { Cymodocea } \\
\text { rotundata }\end{array}$ & $\begin{array}{c}\text { Thalassia } \\
\text { hemprichii }\end{array}$ \\
\hline \multirow{3}{*}{$\mathrm{A}$} & $\mathrm{A} 1$ & 71 & 129 & 101 & - \\
& $\mathrm{A} 2$ & - & 64 & 185 & 51 \\
& $\mathrm{~A} 3$ & 116 & 147 & 36 & - \\
\hline \multirow{2}{*}{$\mathrm{B}$} & $\mathrm{B} 1$ & - & - & 300 & - \\
& $\mathrm{B} 2$ & 122 & - & 178 & - \\
\hline
\end{tabular}


Indeks nilai penting membuktikan bahwa apakah suatu spesies tersebut berperan penting dalam suatu ekosistem tersebut atau tidak. Seperti pada ekosistem lamun, lamun termasuk salah satu ekosistem penting yang ada di perairan selain ekosistem karang dan ekosistem mangrove, sehingga ekosisten ini memiliki peranan yang berfungsi untuk keberlangsungan di suatu ekosistem perairan. Seperti yang dikatakan oleh Tangke (2010), bahwa beberapa fungsi padang lamun, yaitu: 1) sebagai stabilisator perairan dengan fungsi sistem perakannya sebagai perangkap dan penstabil sedimen dasar sehingga perairan menjadi lebih jernih; 2) lamun menjadi sumber makanan langsung berbagai biota laut (ikan dan non ikan); 3) lamun sebagai produser primer; 4) komunitas lamun memberikan habitat penting (tempat hidup) dan perlindungan (tempat berlindung) untuk sejumlah spesies hewan; dan 5) lamun memegang fungsi utama dalam daur zat hara dan elemen langka di lingkungan laut.

\section{KESIMPULAN}

Berdasarkan hasil penelitian yang ditemukan di perairan Pulau Parang terdapat 4 jenis lamun, yaitu Cymodocea rotundata, Enhalus acoroides, Halophila ovalis dan Thalassia hemprichii. Kerapatan tertinggi diperoleh 219 tegakan $/ \mathrm{m}^{2}$ dengan spesies $C$. rotundata sedangkan kerapatan lamun terendah diperoleh 5 tegakan $/ \mathrm{m}^{2}$ dengan spesies $T$. hemprichii. Persentase (\%) penutupan lamun tertinggi pada stasiun B2 diperoleh 32,28\% dan terendah pada stasiun B3 diperoleh 8,75\%. Nilai indeks keanekaragaman kategori sedang untuk lokasi $A$ dan rendah untuk lokasi $B$, indeks keseragaman kategori tinggi untuk lokasi $A$ dan sedang untuk lokasi $B$, dan indeks dominansi lamun kategori sedang untuk lokasi $A$ dan tinggi untuk lokasi B. Indeks Nilai Penting tertinggi diperoleh stasiun B1 dengan nilai 300\% dan terendah stasiun A2 dengan nilai $51 \%$.

\section{DAFTAR PUSTAKA}

Arikunto, S. 2006. Prosedur Penelitian Suatu Pendekatan Praktik. Renika Cipta. Jakarta. $370 \mathrm{hlm}$. Brower, J.E., Zar, J.H. \& von Ende, C.N. 1990. Field and Laboratory Methods for General Ecology $3^{\text {rd }}$ ed., WMV Brown Publisher, Indiana, $237 \mathrm{p}$.

English, S., Wilkinson, C. \& Baker, V. 1994. Survey Manual for Tropical Marine Resources. ASEAN-Australia Marine Science Project: Living Coastal Resources. Australian Institute of Marine Science, Townsville, $368 \mathrm{p}$.

Fachrul, M.F. 2007. Metode Sampling Bioekologi. Jakarta: Bumi Aksara. 87 hlm.

Feryatun, F., Hendrarto, B., Widyorini, N. 2012. Kerapatan dan Distribusi Lamun (Seagrass) Berdasarkan Zona Kegiatan yang Berbeda di Perairan Pulau Pramuka, Kepulauan Seribu. Jurnal of Management of Aquatic Resources. 1(2):1-7.

Hardiyanti, S., Umar, M.R., \& Priosambodo, D. 2009. Analisis Vegetasi Lamun di Perairan Pantai Mara'bombang Kabupaten Pinrang. Jurusan Biologi Fakultas Matematika dan IImu Pengetahuan Alam Universitas Hasanuddin, Makassar.

Hartati, R., Djunaedi A., Hariyadi \& Mujiyanto. 2012. Struktur Komunitas Padang Lamun di Perairan Pulau Kumbang, Kepulauan Karimunjawa. Jurnal IImu Kelautan. 17(4):217-225.

Hemminga M.A \& Duarte, C.M. 2000. Seagrass Ecology. Cambridge University Press, London. $298 \mathrm{p}$.

Irawan, A. \& Matuankotta, C. 2015. Enhalus acoroides, Lamun Terbesar di Indonesia. Oseana, $\mathrm{XL}(1): 19-26$.

Kuo, J. \& den Hartog, C.. 2006. Seagrass Morphology, Anatomy and Ultrastructure. In: Larkum, A.W.D., R.J. Orth \& C.M. Duarte (eds.). Seagrasses: Biology, Ecology and Conservation. Springer, the Netherlands: 51-87.

Nontji, A. 1993. Laut Nusantara. Djambatan. Jakarta. 367.

Nybakken, J.W. 1992. Biologi Laut : Suatu Pendekatan Ekologis. Jakarta: Gramedia Pustaka Utama.

Odum, E.P. 1996. Dasar-dasar Ekologi; Edisi Ketiga.Yogyakarta. Gadjah Mada University Press, Penerjemah Samingan, Tjahjono.

Philips, R.C. \& Menez, E.G. 1998. Seagrasses in : Smithsonian Contribusion to the Marine Science no. 34. Smithsonian Institution Press. Washington, D.C. 
Purnama, P.R., Rahmawati, S. \& Purnobasuki, H. 2013. Pola pertumbuhan Halophila ovalis (R. Brown.) Hooker $f$. dalam Kultur In Vitro. Departemen Biologi Fakultas Sains dan Teknologi Universitas Airlangga, Surabaya. Bioscientiae. 10(2):93-101.

Ruswahyuni. 2008. Hubungan Antara Kelimpahan Meiofauna Dengan Tingkatan Kerapatan Lamun yang Berbeda di Pantai Pulau Panjang, Jepara. Jurnal Saintek Perikanan. 4(1):35-41

Short, F.T. \& Coles, R.G. 2003. Global Seagrass Research Methods. Elsevier Science BV, Amsterdam, $473 \mathrm{p}$.

Supriyadi, I.H., \& Kuriandewa, T.E., 2008. Distribusi Lamun di Pulau - Pulau Kecil: Kepulauan Derawan, Provinsi Kalimantan Timur, Indonesia. Oseanologi dan Limnologi, 34(1):83-99.

Syamsurisal. 2011. Studi Beberapa Indeks Komunitas Makrozoobenthos di Hutan Mangrove Kelurahan Coppo Kabupaten Baru. Fakultas IImu Kelautan dan Perikanan, Universitas Hassanuddin. Makasar.

Tangke, U. 2010. Ekosistem Padang Lamun (Manfaat, Fungsi, Rehabilitasi). Jurnal IImiah agribisnis dan Perikanan. 3(1):9-29

Thomascik, T., Mah, A.J., Nontji, A., \& Moosa, M.K., 1997. The Ecologi Of Indonesian Seas. Part two. The Ecology of Indonesia Series. Volume VII. 